\title{
Highlights on the Golden Mushroom Cantharellus cibarius and unique Shaggy ink cap Mushroom Coprinus comatus and Smoky Bracket Mushroom Bjerkandera adusta Ecology and Biological Activities
}

\section{Elkhateeb WA* and Daba GM}

Chemistry of Natural and Microbial Products Department, Pharmaceutical Industries Division, National Research Centre, Egypt

*Corresponding author: Waill A Elkhateeb, Chemistry of Natural and Microbial Products, Department, Pharmaceutical Industries Division, National Research Centre, Dokki, Giza, 12622, Egypt, Tel: +201013241936; Fax: +20233370931; Email: waillahmed@yahoo.com

\section{Review Article}

Volume 4 Issue 2

Received Date: August 04, 2021

Published Date: August 24, 2021

DOI: $10.23880 /$ oajmms-16000143

\section{Abstract}

Mushrooms are generous source of nutritional and medicinal compounds, and medicinal uses of the mushrooms still need to be worked out for their biological activities. This review aims to put golden mushroom Cantharellus and shaggy ink cap mushroom Coprinus and smoky bracket mushroom Bjerkandera under light spot through describing their morphology and ecology especially of the most common species, Cantharellus cibarius; Coprinus comatus and Bjerkandera adusta. Moreover discussing important secondary metabolites and biological activities exerted by ever one. Cantharellus cibarius; Coprinus comatus and Bjerkandera adusta are able to produce many novel and potent secondary metabolites that exerted different bioactivities especially as antimicrobial, antitumor, anti-inflammation activities and others. Further studies and investigations are fortified in order to find more about these interesting mushrooms.

Keywords: Medicinal Mushrooms; Cantharellus cibarius; Coprinus comatus; Bjerkandera adusta; Biological Activities

\section{Introduction}

Mushrooms have been consumed since earliest history, for centuries, the Chinese culture has treasured mushrooms as a health food, an elixir of life, hey have been part of the human culture for thousands of years and have considerable interest in the most important civilizations in history because of their sensory characteristics; they have been recognized for their attractive culinary attributes. Nowadays, mushrooms are popular valuable foods because they are low in calories, carbohydrates, fat, and sodium: also, they are cholesterol-free besides [1,2].
Mushrooms have been considered as ingredient of gourmet cuisine across the globe, and have been valued by humankind as a cooking wonder. More than 2,000 species of mushrooms exist in nature, but around 25 are widely accepted as food and few are commercially cultivated. Mushrooms are considered as a delicacy with high nutritional and functional value, and they are also accepted as nutraceutical foods; they are of considerable interest because of their organoleptic merit, medicinal properties, and economic significance [3]. However, there is not an easy distinction between edible and medical mushrooms because many of the common edible species have therapeutic properties and several used 


\section{Open Access Journal of Mycology \& Mycological Sciences}

for medical purposes are also edible [4]. Mushrooms could be an alternative source of new antimicrobial compounds, mainly secondary metabolites, such as terpenes, steroids, anthraquinones, benzoic acid derivatives, and quinolones, but also of some primary metabolites like oxalic acid, peptides, and proteins. A large variety of mushrooms have been utilized traditionally in many different cultures for the maintenance of health, as well as in the prevention and treatment of diseases through their immunomodulatory and antineoplastic properties. In the last decade, the interest for pharmaceutical potential of mushrooms has been increased rapidly, and it has been suggested that many mushrooms are like mini-pharmaceutical factories producing compounds with miraculous biological properties $[5,6]$.

All together with a long history as food source, mushrooms are important for their healing capacities and properties in traditional medicine [7-15]. It has reported beneficial effects for health and treatment of some diseases. Many nutraceutical properties are described in mushrooms, such as prevention or treatment of Parkinson, Alzheimer, hypertension, and high risk of stroke. They are also utilized to reduce the possibility of cancer invasion and metastasis due to antitumoral attributes. Mushrooms act as antibacterial, immune system enhancer and cholesterol lowering agents; additionally, they are important sources of bioactive compounds. Mushrooms provide important nutrients, including selenium, potassium, ribolavin, niacin, vitamin D, proteins. As a result of these properties, some mushroom extracts are used to promote human health and are found as dietary supplements [16-34].

\section{Cantharellus cibarius}

Cantharellus cibarius Fr. (Basidiomycota), commonly known as Chanterelle, is one of the most valued and currently most often collected species of edible mushrooms in Europe, Asia, Africa, and the northern USA. Cantharellus cibarius belonging to; Basidiomycota; Class: Agaricomycetes; Order: Cantharellales; Family: Cantharellaceae. Yellow to orangeyellow or orange mushrooms found in hardwood forests, featuring a broadly curved, flat, or shallowly depressed cap, a central and fleshy stem, and false gills on the underside of the cap. Cantharellus cibarius mushrooms are also known for their fruity, apricot-like odor, best detected when you have several of them together in your collection bag or basket. In western North America, there appears to be less diversity among the cibarius-like species; so far, anyway, only four species have been delineated with contemporary species concepts [34], and from Buyck B, et al. [35,36]. Spore print color white, creamy, yellow, pinkish, and deep pinkish. Color of False Gills, the whitish young false gills of Cantharellus sp. develops pink shades as the spores mature. The color of the false gills can be difficult to assess, and even more difficult to photograph (Figures $1 \& 2$ ) [37].

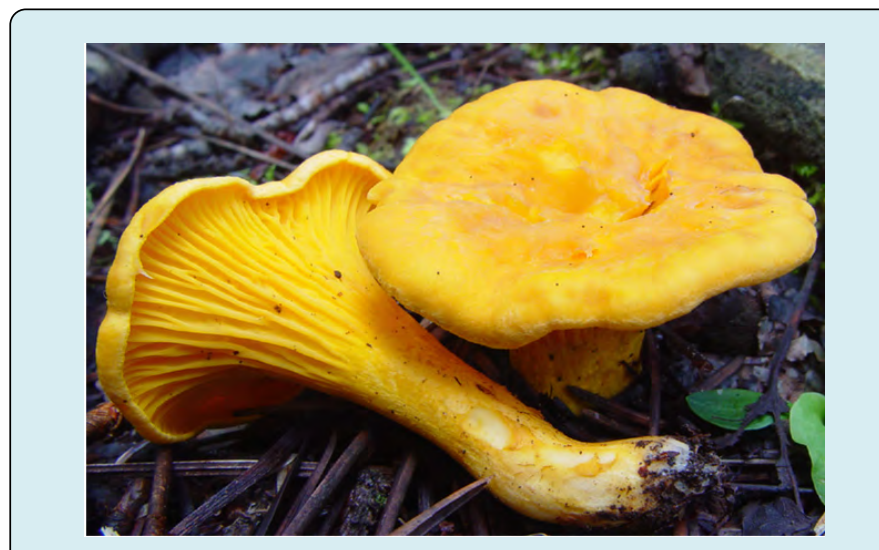

Figure 1: Cantharellus cibarius, (Photo was taken by: Scott T. Bates. Locality: USA, Arizona, White Mountains, Hannagan Meadow.

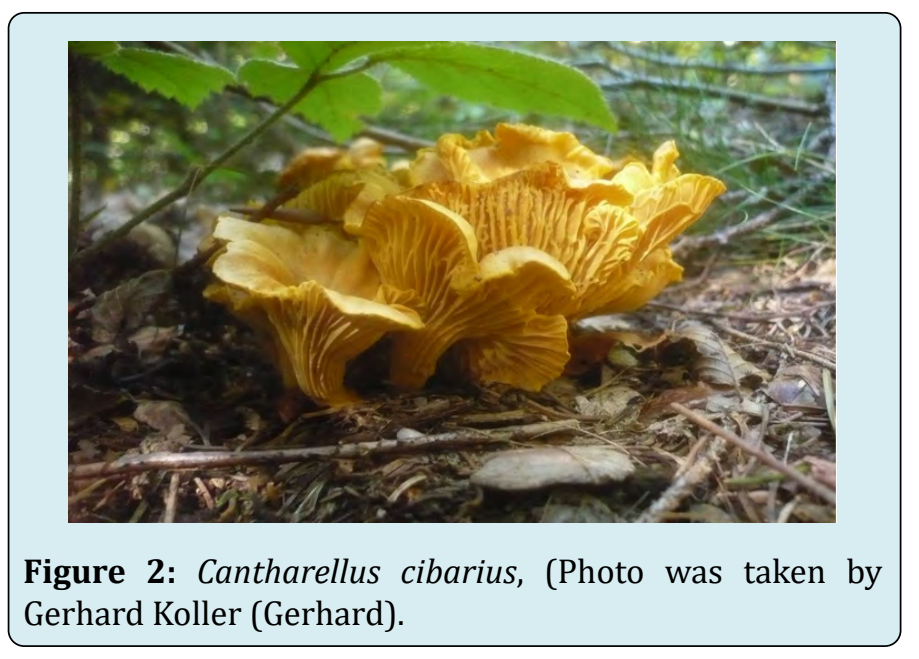

\section{Cantharellus cibarius Biological Activities}

One of the most commonly consumed mushrooms is Cantharellus cibarius, also known as golden girolle or chanterelles. Polysaccharide is one of the important active ingredients of Cantharellus cibarius [38]. Therefore, the investigation of the pro-health properties of crude polysaccharides from this genus and species was performed by many researchers. The obtained results indicate that the polysaccharide fraction from Cantharellus cibarius inhibits the activity of both COX-1 and COX-2. Crude polysaccharides extracted from Cantharellus cibarius were found to inhibit the proliferation of colon cancer cells with the simultaneous absence of toxicity towards normal cells. The presented activities indicate for the first time that this edible mushroom possesses interesting chemo-preventive potential, especially against colon cancer $[39,40]$. 


\section{Open Access Journal of Mycology \& Mycological Sciences}

Antibacterial and cytotoxic activities of cyclohexane, dichloromethane, methanol, and aqueous extracts of Cantharelluscibariuswerestudied by Kolundzic M, etal. [40]. Broth microdilution assay was performed against 10 bacterial strains (Staphylococcus aureus, S. epidermidis, Micrococcus luteus, Bacillus subtilis, Enterococcus feacalis, Escherichia coli, Klebsiella pneumoniae, Pseudomonas aeruginosa, Salmonella abony), with stress on Helicobacter pylori. Methanol extract was the most active against Helicobacter pylori strains with minimal inhibitory concentration values. All extracts were active against antibiotic resistant Helicobacter pylori. Chemical analysis of Cantharellus cibarius methanolic crude extract has shown the presence of linoleic, cis-vaccenic, and oleic acids, sterols, $\beta$-glucans, and polyphenolic compounds [41]. The medicinal and health benefits, observed in wild $C$. cibarius mushroom, seem an additional reason for its traditional use as a popular delicacy food [42].

The methanolic extract of the wild edible mushroom Cantharellus cibarius Fr. (chanterelle) was studied by Kozarski M, et al. [42], and analyzed for in vitro antioxidative, cytotoxic, antihypertensive and antibacterial activities. Various primary and secondary metabolites were found. Phenols were the major antioxidant components found in the extract, followed by flavonoids, whose content was approximately $86 \%$ of the total phenol content. Antioxidant activity, measured by four different methods, was high for inhibition of lipid peroxidation and chelating ability. The antioxidant activity of the $C$. cibarius methanol extract was achieved through chelating iron compared to hydrogen atom and/or electron transfer. The extract showed good selectivity in cytotoxicity on human cervix adenocarcinoma HeLa, breast carcinoma MDAMB-453 and human myelogenous leukemia K562, compared to normal control human fetal lung fibroblasts MRC-5 and human lung bronchial epithelial cells BEAS-2B.

The golden chanterelle edible mushroom, Cantharellus cibarius, has medicinal value. Given that this species has good radical scavenging activity and strong antioxidant potential and bactericidal effects beside that anti-inflammatory activity. Nasiry D, et al. [43] reported that, Significant woundhealing activity in each wound model was observed in the Cantharellus cibarius extract-treated and Madecassol-treated groups compared with the nontreated and vehicle-treated groups. Histological assessment showed complete repair of the epidermal layer, increased collagen production, and a remarkable degree of neovascularization and epithelization in the extract group, which were significantly different from those in the other groups. Therefore, Cantharellus cibarius methanolic crude extract showed significant wound-healing and anti-inflammatory effects, which could be the scientific rationale for the medicinal use of the golden chanterelle mushroom in treating wounds [44].

\section{Coprinus comatus Shaggy ink cap Mushroom}

Mushrooms have been used for centuries not only as food but also in traditional medicine as a source of components with pro-health activity. One of them is Coprinus comatus also called shaggy mane, shaggy ink cap, chicken drumstick mushroom, or lawyer's wig. In Asian countries, Coprinus comatus is approved as edible mushroom and often cultivated for consumption, whereas in many other countries, although it is widespread, it is unrecognized and not used. Various studies show many of the biological activities by Coprinus comatus, such as antioxidant, anticancer, antiandrogenic, hepatoprotective, acetylcholinesterase inhibitory, antiinflammatory, antidiabetic, antiobesity, antibacterial, antifungal, antinematode, and antiviral [45-48].

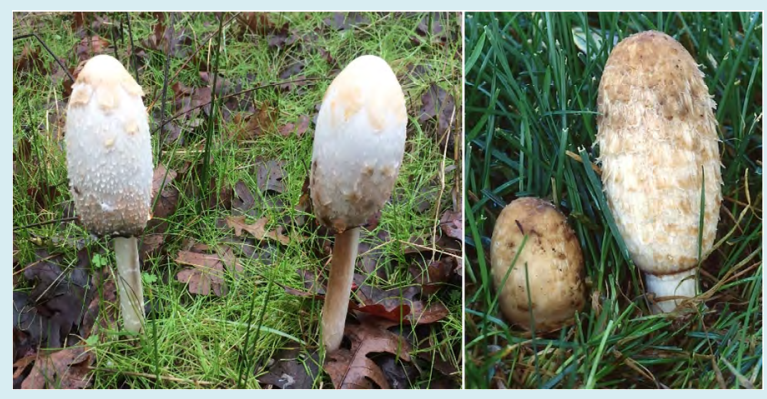

Figure 3: Coprinus comatus, Photo was taken by: Vera S. Evenson. Locality: USA, Colorado, Aspen; Hosted by: http://mycoportal.org).

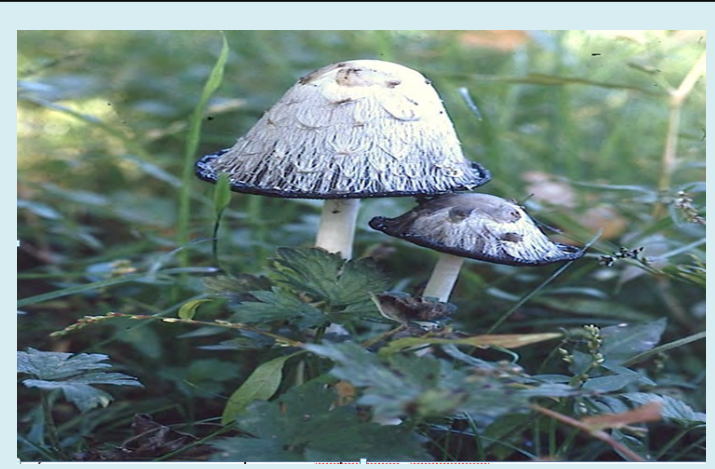

Figure 4: Coprinus comatus, Photo was taken by: Vera S. Evenson. Locality: USA, Colorado, Aspen; Hosted by: http://mycoportal.org).

Coprinus comatus belonging to Basidiomycota, Class; Agaricomycetes, Order; Agaricales, Family; Agaricaceae. Coprinus comatus mushroom appear in troops or lines or rings, this mushroom is well known and relatively easily recognized. Its unique features include its shape and stature, and the fact that the gills "deliquesce," turning themselves into black ink as they mature. DNA studies over the last 


\section{Open Access Journal of Mycology \& Mycological Sciences}

decade make it clear that Coprinus comatus is closely related to species of Agaricus and Lepiota. The genus Coprinus, which once held all such mushrooms, now holds only Coprinus comatus and a few similar mushrooms, and it turns out that the presence of a ring on the stem and a string-like strand of fibers inside the stem's hollow cavity (Figure 3\&4) turn out to be better predictors of the genus Coprinus than deliquescing gills. Coprinus comatus growing as saprobic, alone or in clusters, lines, or fairy rings on lawns, wood chips, or hard-packed ground; summer and fall; widely distributed in North America. Cap: $3-15 \mathrm{~cm}$; oval to rounded-cylindrical when young, expanding to bell-shaped with a lifting margin; in age turning to black "ink"; dry; whitish with a brownish center; with large, shaggy scales; margin lined at maturity. Gills: Free from the stem; white, becoming pinkish, then black turning to black "ink"; very crowded. Stem: $5-20 \mathrm{~cm}$ long; $1-2 \mathrm{~cm}$ thick; frequently tapering to apex; smooth; white; easily separable from cap; hollow, with a string-like strand of fibers hanging inside. Body flesh white throughout and soft. Odor and taste not distinctive. Spore color Black.

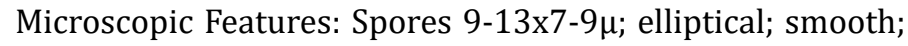
with a central to slightly eccentric pore. Basidia 4-spored; surrounded by brachybasidia. Pleurocystidia absent. Cheilocystidia variously shaped; up to $60 \times 40 \mu$. Pileipellis cutis-like. Veil elements cylindric; 7-30 $\mu$ wide [49-52].

\section{Coprinus comatus Biological Activities and Therapeutic Food}

Coprinus comatus, an edible and medicinal mushroom, not only tastes delicious, but also has various pharmacological activities [51]. Recently, it has been reported that researchers have extracted more and more active ingredients, including polysaccharides, comatin, active protein complexes, and phenols from fruit bodies, mycelium, or fermentation liquor of Coprinus comatus and studied their corresponding functions. Cao $\mathrm{H}$, et al. [51], summarizes not only the hypoglycemic effect of Coprinus comatus, but also other functions, such as antioxidant activity, alcohol liver protection, cancer inhibition, antiandrogenic function, antiinflammatory effect, treatment of leukemia, and so on, which will provide scientific basis for the deep processing and comprehensive utilization of Coprinus comatus.

Mushrooms have been reported as sources of biomolecules with various potential. Coprinus comatus was studied by Stojkovic D, et al. [52], Coprinus comatus methanolic extract was tested for its antioxidant potential (reducing power, radical scavenging activity and lipid peroxidation inhibition) and antimicrobial properties (tested against Gram positive and negative bacteria, and microfungi). Both studied samples (Cultivated and wild Coprinus comatus) revealed similar nutritional value and energy contribution. The cultivated Coprinus comatus revealed the highest content in free sugars, monounsaturated fatty acids and tocopherols, while the wild Coprinus comatus mushroom was richer in saturated and polyunsaturated fatty acids, organic acids and phenolic compounds. The cultivated Coprinus comatus also revealed the highest antioxidant potential and antimicrobial activity (with exception towards Gram negative bacteria and Aspergillus ochraceus). Stojkovic D, et al. [52] reported that cultivated and wild mushrooms from the same species could be excellent options as food and as sources of nutritional and bioactive compounds.

Coprinus comatus, also called chicken drumstick mushroom, is currently commercially available in China. Hot water and ethanolic extracts were prepared from cap and stipe of $C$. comatus fruit bodies and their antioxidant properties were studied by Li B, et al. [53]. Ethanolic extract from stipe showed high antioxidant activity $(80.6 \%)$ at $1 \mathrm{mg} / \mathrm{mL}$. Reducing power of hot water extracts from cap was 1.653 at $10 \mathrm{mg} / \mathrm{mL}$. Extracts from cap showed better scavenging ability on DPPH $(57.9 \%$ at $1 \mathrm{mg} / \mathrm{mL})$ than stipe ones. Ethanolic extracts were more effective in scavenging ability on hydroxyl radicals $(57.4-61.3 \%$ at $5 \mathrm{mg} / \mathrm{mL}$ ) than hot water extracts. Naturally occurring antioxidant components including total phenols $(3.60-20.00 \mathrm{mg} / \mathrm{g})$, tocopherols $(0.58-11.93 \mathrm{mg} / \mathrm{g})$, flavonoids $(0.19-3.52 \mathrm{mg} / \mathrm{g})$ and polysaccharides $(58.52-547.86 \mathrm{mg} / \mathrm{g}$ ) were found in Coprinus comatus methanolic extracts. Alkalic-extractable polysaccharides (ALPS) from Coprinus comatus, was studied by Zhao $\mathrm{H}$, et al. [54], to explore it's in vivo antioxidant activities and protective effects on alcohol-induced liver injury. Alkalicextractable polysaccharides showed strong antioxidant and anti-inflammatory abilities and low serum enzyme activities, hepatic and serum lipid levels, as well as low hepatic lipid peroxidation levels; moreover, Alkalic-extractable polysaccharides improved the alcohol metabolism system. These results may offer support for the use of Alkalicextractable polysaccharides as a functional food or natural drug source that can prevent and treat alcohol-induced liver injury.

Stilinovic N, et al. [55], investigated the chemical and nutritional profile and antioxidative properties of cultivated Coprinus comatus. Nearby analysis revealed that Coprinus comatus is rich in carbohydrates, dietary fibres and proteins, and could also be a valuable source of phenolics. Additionally, fat content is low, consisting mainly of polyunsaturated and omega-3 fatty acids. Oral treatment with Coprinus comatus for 42 days improved the antioxidant capabilities and ameliorated carbon tetrachloride induced liver damage in rats, marked by decreased serum aminotransferase levels and lipid peroxidation intensity. Histological morphometric and immunohistochemical analysis confirmed antioxidative and hepatoprotective potential. These findings suggest that cultivated Coprinus comatus could be considered a 


\section{Open Access Journal of Mycology \& Mycological Sciences}

nutraceutical, having beneficial nutrient and therapeutic properties [55]. In order to determine the nutraceutical and pharmacological potential of Philippine wild strain of Coprinus comatus, the antibacterial property, phytochemical composition, and antioxidant activity were evaluated by Kalaw SP, et al. [56], both ethanol and acetone basidiocarp extracts exhibited antibacterial activity against Staphylococcus aureus. Coprinus comatus ethanol extract produced wider zone of inhibition than acetone extract. Phytochemical screening revealed the presence of alkaloids, flavonoids, saponins and terpenoids in Coprinus comatus mushroom.

\section{Bjerkandera adusta}

Bjerkandera adusta belonging to; Basidiomycota; Class: Agaricomycetes; Order: Polyporales; Family: Meruliaceae. This interesting polypore mushroom has a striking, dark gray to black pore surface that contrasts with its pale cap surface. It is a common decomposer of the deadwood of hardwoods, widely distributed across the continent. Ecology: Saprobic on the deadwood of hardwoods and, rarely, conifers; causing a white rot, widely distributed throughout North America. Cap: Bracket-like to shelf-like, or merely a turned-over edge above a spreading pore surface or occasionally lacking entirely; semicircular to irregular in outline; convex to flat; to about $10 \mathrm{~cm}$ wide and $6 \mathrm{~cm}$ deep; velvety to finely hairy, becoming bald with maturity; whitish to grayish, tan, or brownish; sometimes zoned; when mature with a brown to black margin. Pore Surface: Gray to black; sometimes bruising darker black; with 6-7 tiny, angular pores per $\mathrm{mm}$; tubes to $2 \mathrm{~mm}$ deep. Stem: Absent. Flesh: Whitish to faintly brownish; tough and corky or leathery. Odor and Taste: Odor fragrant, or not distinctive. Taste sour, or not distinctive. Spore Print: White. Microscopic Features: Spores 4-6 x 2.5-3.5 $\mu$; smooth; elliptical; inamyloid. Cystidia absent. Hyphal system monomitic; hyphae with abundant clamp connections (Figures $5 \& 6$ ) [57,58].

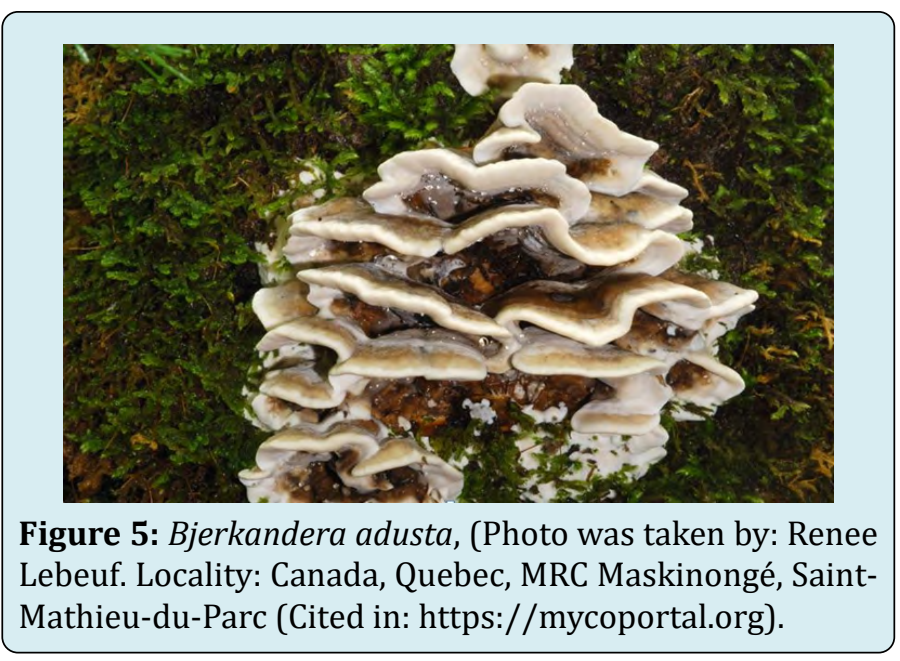

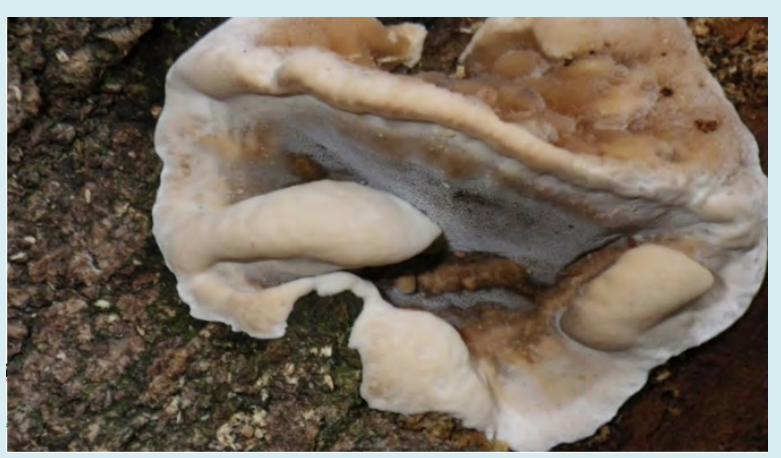

Figure 6: Bjerkandera adusta, (Photo was taken by Dominic. Locality: United States, California, Lodi Lake Park, Lodi, San Joaquin County, California (Cited in: https:// mycoportal.org).

\section{Bjerkandera adusta Biological Activities}

Many Ascomycetes and Basidiomycetes have been reported as producers of antibacterial, antifungal and insecticidal compounds, which they use to protect themselves against unwanted microorganisms and insects in their natural environments $[59,60]$. These bioactive compounds could therefore be isolated from edible and inedible mushrooms. Akata I, et al. [61], reported that antagonistic effects of Bjerkandera adusta crude extracted by methanol were found against Fusarium inflexum, Fusarium heterosporium. This was obtained by the clear zone of inhibition produced by the fungi around the tested mushroom extracts. An antifungal activity of Bjerkandera adusta extracts was high at the Fusarium inflexum than Fusarium heterosporium.

The antimicrobial potential of Bjerkandera adusta solvent extracts were evaluated on some selected bacteria. Some solvent extracts of Bjerkandera adusta were very effective against three Gram-negative bacteria (Escherichia coli, Salmonella typhimurium and Pseudomonas aeruginosa) and three Gram-positive bacteria (Staphylococcus aureus, Staphylococcus epidermidis and Bacillus cereus). The effectiveness of Bjerkandera adusta solvent extracts as antibacterial agents should be well explored with development of optimized methods for mass production of this macrofungi in controlled environments [62]. Because Bjerkandera adusta produces important enzymes that can degrade polycyclic aromatic hydrocarbons, such as those used in synthetic textile dyes, there has been research interest in investigating the fungus for possible use in bioremediation $[63,64]$.

\section{Conclusion}

Basidiomycetous mushrooms represented by Cantharellus cibarius, Coprinus comatus and Bjerkandera 


\section{Open Access Journal of Mycology \& Mycological Sciences}

adusta have a rich history of use as an edible source and well-claimed medicinal properties. This review summarises a number of sources with details of nutritional content and beneficial compounds (Antimicrobial, antioxidant properties to antitumor, health-promoting sterols and others). Despite these advances, there is much we have yet to understand and these hypogeal fruiting Basidiomycetes prove to be a fruitful source of novel medicinal compounds.

\section{References}

1. Miles PG, Chang ST (2004) Mushrooms: cultivation, nutritional value, medicinal effect, and environmental impact. CRC press.'

2. Ergonul PG, Akata I, Kalyoncu F, Ergonul B (2013) Fatty acid compositions of six wild edible mushroom species. The Scientific World Journal 1-10.]

3. Guillamon E, Lafuente AG, Lozano M, Rostagno MA, Villares A, et al. (2010) Edible mushrooms: role in the prevention of cardiovascular diseases. Fitoterapia 81(7): 715-723.

4. Patel S, Goyal A (2012) Recent developments in mushrooms as anti-cancer therapeutics: a review. 3 Biotech 2(1): 1-15.

5. Zaidman BZ, Yassin M, Mahajna J, Wasser SP (2005) Medicinal mushroom modulators of molecular targets as cancer therapeutics. Applied Microbiology and Biotechnology 67(4): 453-468.

6. Valverde ME, Perez TH, Lopez OP (2015) Edible mushrooms: improving human health and promoting quality life. International journal of microbiology 1-16.

7. Elkhateeb WA, Daba GM, Thomas PW, Wen TC (2019) Medicinal mushrooms as a new source of natural therapeutic bioactive compounds. Egypt Pharmaceu J 18(2): 88-101.

8. Elkhateeb WA, Daba GM, Elnahas M, Thomas P, Emam M (2020) Metabolic profile and skin-related bioactivities of Cerioporus squamosus hydromethanolic extract. Biodiversitas J Biological Div 21(10): 4732-4740.

9. Elkhateeb WA, Daba G (2020) Review: the endless nutritional and pharmaceutical benefits of the Himalayan gold, Cordyceps; Current knowledge and prospective potentials. Asian Journal of Natural Product Biochemistry 18(2): 70-77.

10. Elkhateeb WA, Daba GM (2020) Termitomyces Marvel Medicinal Mushroom Having a Unique Life Cycle. Open Access Journal of Pharmaceutical Research 4(1): 1-4.
11. Daba GM, Elkhateeb W, EL Dien AN, Fadl E, Elhagrasi A, et al. (2020) Therapeutic potentials of n-hexane extracts of the three medicinal mushrooms regarding their anticolon cancer, antioxidant, and hypocholesterolemic capabilities. Biodiversitas Journal of Biological Diversity 21(6): 2437-2445.

12. Elkhateeb WA (2020) What medicinal mushroom can do? Chem Res J 5(1): 106-118.

13. Elkhateeb WA, Daba GM, Elmahdy EM, Thomas PW, Wen TC, et al. (2019) Antiviral potential of mushrooms in the light of their biological active compounds. ARC J Pharmac Sci 5: 45-49.]

14. El-Hagrassi A, Daba G, Elkhateeb W, Ahmed E, El-Dein AN, et al. (2020) In vitro bioactive potential and chemical analysis of the $\mathrm{n}$-hexane extract of the medicinal mushroom, Cordyceps militaris. Malays J Microbiol 16(1): 40-48.

15. Elkhateeb WA, Daba GM, El-Dein AN, Sheir DH, Fayad W, et al. (2020) Insights into the in-vitro hypocholesterolemic, antioxidant, antirotavirus, and anticolon cancer activities of the methanolic extracts of a Japanese lichen, Candelariella vitellina, and a Japanese mushroom, Ganoderma applanatum. Egyptian Pharmaceutical Journal 19(1): 67-73.

16. Elkhateeb WA, Elnahas MO, Thomas PW, Daba GM (2019) To Heal or Not to Heal? Medicinal Mushrooms Wound Healing Capacities. ARC Journal of Pharmaceutical Sciences 5(4): 28-35.

17. Elkhateeb WA, Daba GM, Elnahas MO, Thomas PW (2019) Anticoagulant capacities of some medicinal mushrooms. ARC J Pharma Sci 5(4): 1-9.'

18. Elkhateeb W, Elnahas MO, Paul W, Daba GM (2020) Fomes fomentarius and Polyporus squamosus models of marvel medicinal mushrooms. Biomed Res Rev 3: 119 .

19. Elkhateeb WA, Daba GM (2021) Mycotherapy of the good and the tasty medicinal mushrooms Lentinus, Pleurotus, and Tremella. Journal of Pharmaceutics and Pharmacology Researchs 4(3): 1-6.

20. Elkhateeb WA, Daba GM (2021) The Fascinating Bird's Nest Mushroom, Secondary Metabolites and Biological Activities.' International Journal of Pharma Research and Health Sciences 9(1): 3265-3269.

21. Elkhateeb WA, Daba GM, and Gaziea SM (2021) The AntiNemic Potential of Mushroom against Plant-Parasitic Nematodes. Open Access Journal of Microbiology \& Biotechnology 6(1): 1-6. 


\section{Open Access Journal of Mycology \& Mycological Sciences}

22. Elkhateeb WA, Elnahas MO, Thomas PW, Daba GM (2020) Trametes Versicolor and Dictyophora Indusiata Champions of Medicinal Mushrooms. Open Access Journal of Pharmaceutical Research 4(1): 1-7.

23. Daba GM, Elkhateeb W, ELDien AN, Fadl E, Elhagrasi A, et al. (2020) Therapeutic potentials of n-hexane extracts of the three medicinal mushrooms regarding their anticolon cancer, antioxidant, and hypocholesterolemic capabilities. Biodiversitas Journal of Biological Diversity 21(6): 1-10.'

24. Thomas PW, Elkhateeb WA, Daba GM (2020) Chaga (Inonotus obliquus): a medical marvel but a conservation dilemma?. Sydowia 72: 123-130.

25. Sharma SK, Gautam N (2017) Chemical and bioactive profiling, and biological activities of coral fungi from north-western Himalayas. Scientific reports 7(1): 1-13.

26. Jais HM, Tajuddin R, Iffendy KA (2014) Macrofungi of a Healty Campus (Penerbit USM). Penerbit USM.'

27. Kuo M, Methven A.(2010) 100 cool mushrooms. University of Michigan Press.]

28. Kamalakannan A, Syamala M, Sankar P, Shreedevasena M, Ajay M (2020) Mushrooms-A Hidden Treasure. JPS Scientific Publications, pp: 1-136.

29. Cheung PC (2010) The nutritional and health benefits of mushrooms. Nut Bull 35(4): 292-299.

30. Hobbs C (2002) Medicinal mushrooms: an exploration of tradition, healing, and culture. Book Publishing Company, pp: 1-402.

31. Rathee S, Rathee D, Rathee D, Kumar V, Rathee P (2011) Mushrooms as therapeutic agents. Braz J Pharmacog 22: 459-474.

32. Rahi D, Malik D (2016) Diversity of mushrooms and their metabolites of nutraceutical and therapeutic significance. J Mycol 1-19.

33. Buyck B, Hofstetter V (2011) The contribution of tef-1 sequences to species delimitation in the Cantharellus cibarius complex in the southeastern USA. Fungal Diversity 49(1): 35-46.'

34. Foltz MJ, Perez KE, Volk TJ (2013) Molecular phylogeny and morphology reveal three new species of Cantharellus within $20 \mathrm{~m}$ of one another in western Wisconsin, USA. Mycologia 105(2): 447-461.

35. Buyck B, Olariaga I, Looney B, Justice J, Hofstetter V (2016) Wisconsin chanterelles revisited and first indications for very wide distributions of Cantharellus species in the United States East of the Rocky Mountains. Cryptogamie, Mycologie 37(3): 345-366.'

36. Buyck B, Antonin V, Chakraborty D, Baghela A, Das $\mathrm{K}$, et al. (2018) Cantharellus sect. Amethystini in Asia. Mycological Progress 17(8): 917-924.)

37. Chen L, Peng X, Lv J, Liao S, Ou S, et al. (2017) Purification and structural characterization of a novel water-soluble neutral polysaccharide from Cantharellus cibarius and its immunostimulating activity in RAW264. 7 cells. International Journal of Polymer Science, pp: 1-10.

38. Jechalke NN, Nowak R, Juda M, Malm A, Lemieszek M, et al. (2018) New biological activity of the polysaccharide fraction from Cantharellus cibarius and its structural characterization. Food chemistry 268: 355-361.

39. Vlasenko V, Turmunkh D, Ochirbat E, Budsuren D, Nyamsuren K, et al. (2019) Medicinal potential of extracts from the chanterelle mushroom, Cantharellus cibarius (Review) and prospects for studying its strains from differs plant communities of ultracontinental regions of the Asia. In BIO Web of Conferences 16: 00039.

40. Kolundzic M, Stanojkovic T, Radovic J, Tacic A, Dodevska $\mathrm{M}$, et al. (2017). Cytotoxic and antimicrobial activities of Cantharellus cibarius Fr. (Cantarellaceae). Journal of medicinal food 20(8): 790-796.

41. Dulger B, Gonuz A, Gucin F (2004) Antimicrobial activity of the macro fungus Cantharellus cibarius. Pakistan Journal of Biological Sciences 7(9): 1535-1539.]

42. Kozarski M, Klaus A, Vunduk J, Zizak Z, Niksic M, et al. (2015) Nutraceutical properties of the methanolic extract of edible mushroom Cantharellus cibarius (Fries): primary mechanisms. Food \& function 6(6): 1875-1886.

43. Nasiry D, Khalatbary AR, Ebrahimzadeh MA (2017) Anti-inflammatory and wound-healing potential of golden chanterelle mushroom, Cantharellus cibarius (Agaricomycetes). International journal of medicinal mushrooms 19(10): 1-10.

44. Luo H, Mo M, Huang X, Li X, Zhang K (2004) Coprinus comatus: a basidiomycete fungus forms novel spiny structures and infects nematode. Mycologia 96(6): 1218-1224.

45. Wang HG, Guan HQ, LI XH (2007) Biologic effect of Coprinus comatus [J]. Chinese Journal of Mycology 6.]

46. Tsai SY, Tsai HL, Mau JL (2009) Antioxidant properties of Coprinus comatus. Journal of Food Biochemistry 33(3): 368-389.) 


\section{Open Access Journal of Mycology \& Mycological Sciences}

47. Dotan N, Wasser S, Mahajna J (2011) The culinarymedicinal mushroom Coprinus comatus as a natural antiandrogenic modulator. Integrative Cancer Therapies 10(2): 148-159.]

48. Barron G, Hsiang T (1999) Fungi on fairways. Golf Course Management 67: 58-61.

49. Imtiaj A, Tae Soo L, Shoji O (2010) Exploration on Filamentous Phenotype of Coprinus comatus Collected form Different Ecological Origins. J Fac Agr Kyushu Univ 55(2): 203-207.

50. Toubi AR, Wasser SP, Fares F (2015) The shaggy ink cap medicinal mushroom, Coprinus comatus (higher Basidiomycetes) extract induces apoptosis in ovarian cancer cells via extrinsic and intrinsic apoptotic pathways. Int J Med Mushrooms 17(12): 1127-1136.

51. Cao H, Qin D, Guo H, Cui X, Wang S, et al. (2020) The shaggy ink cap medicinal mushroom, Coprinus comatus (Agaricomycetes), a versatile functional species: A review. International Journal of Medicinal Mushrooms 22(3): 245-255.

52. Stojkovic D, Reis FS, Barros L, Glamoclija J, Ciric A, et al. (2013) Nutrients and non-nutrients composition and bioactivity of wild and cultivated Coprinus comatus (OF Müll.) Pers. Food and Chemical Toxicology 59: 289-296.)

53. Li B, Lu F, Suo X, Nan H, Li B (2010) Antioxidant properties of cap and stipe from Coprinus comatus. Molecules 15(3): 1473-1486.

54. Zhao H, Zhang J, Liu X, Yang Q, Dong Y, et al. (2018) The antioxidant activities of alkalic-extractable polysaccharides from Coprinus comatus on alcoholinduced liver injury in mice. Scientific reports 8(1): 1-12.

55. Stilinovic N, Capo I, Vukmirovic S, Raskovic A, Tomas A, et al. (2020) Chemical composition, nutritional profile and in vivo antioxidant properties of the cultivated mushroom Coprinus comatus. Royal Society open science 7(9): 200900.]

56. Kalaw SP, Albinto RF (2014) Functional activities of
Philippine wild strain of Coprinus comatus (OF Müll.: Fr.) Pers and Pleurotus cystidiosus OK Miller grown on rice straw based substrate formulation. Mycosphere 5(5): 646-655.

57. Kowalska TK, Wrzosek M, Ginalska G, Iglik H, Bancerz $R$ (2006) Identification and application of a new fungal strain Bjerkandera adusta R59 in decolorization of daunomycin wastes. Enzyme and microbial technology 38(5): 583-590.

58. Kowalska TK, Tkaczyk KR (2019) Growth conditions, physiological properties, and selection of optimal parameters of biodegradation of anticancer drug daunomycin in industrial effluents by Bjerkandera adusta CCBAS930. International Microbiology 23: 287301 .

59. Quang DN, Hashimoto T, Asakawa $Y$ (2006) Inedible mushrooms: A good source of biologically active substances. Chem Record 6(2): 79-99.

60. Jonathan SG (2019) Fungi here, fungi there, fungi everywhere: unique and unparalleled contributions of fungi to environment, food production and medicine. Inaugural lecture, pp: 91.

61. Akata İ, Guler P, Kunduz I (2009) Antifungal effects of Bjerkandera adusta (willd.) p. karst. against to the plant pathogens. Kafkas Universitesi Fen Bilimleri Enstitüsü Dergisi 2(1): 5-8.

62. Chikwem J, Jonathan G, Hull A, Asemoloye M, Osonubi 0, et al. (2020) Antimicrobial Potential of Trichaptum biforme and Bjerkandera adusta from Pennsylvania. Journal of Natural Sciences Research 11(16): 1-10.

63. Singh R, Eltis LD (2015) The multihued palette of dyedecolorizing peroxidases. Archives of Biochemistry and Biophysics 574: 56-65.

64. Kadri T, Rouissi T, Kaur B, Satinder C, Maximiliano S, et al. (2017) Biodegradation of polycyclic aromatic hydrocarbons (PAHs) by fungal enzymes: A review. Journal of Environmental Sciences 51: 52-74. 